\title{
Language Attitudes of Millennials towards Indonesian
}

\author{
Jessie Mulyanie ${ }^{1}$, Rahmawati $^{2}$, Rifna Merisha $^{3}$, Yulianeta $^{4}$ \\ \{jessiemulyanie@upi.edu ${ }^{1}$,rahma1a@upi.edu ${ }^{2}$, rifnamerisha@upi.edu ${ }^{3}$, yaneta@upi.edu $\}$ \\ Universitas Pendidikan Indonesia, Bandung, Indonesia
}

\begin{abstract}
This research was motivated by the existence of competition between Indonesian, regional, and foreign languages. This study aimed to determine the language attitude of the millennial community towards Indonesian. This research was a quantitative-descriptive study with a sociolinguistic theoretical approach. Data were analyzed using the analysis model of Miles and Huberman. The research data consisted of primary and secondary data. Primary data were collected through a questionnaire, while secondary data were sourced from the literatures that supported the research. The results showed that the millennial community had positive language attitudes towards Indonesian. This means that the millennial community still intensively uses Indonesian in their daily lives.
\end{abstract}

Keywords: Indonesian, language attitudes, millennials.

\section{Sikap Bahasa Masyarakat Milenial terhadap Bahasa Indonesia}

\begin{abstract}
Abstrak. Penelitian ini dilatarbelakangi adanya persaingan antara bahasa Indonesia, bahasa daerah, dan bahasa asing. Penelitian ini bertujuan untuk mengetahui sikap bahasa masyarakat milenial terhadap bahasa Indonesia. Penelitian ini merupakan penelitian kuantitatif-deskriptif dengan pendekatan teoretis Sosiolinguistik. Data dianalisis menggunakan model analisis Miles dan Huberman. Data penelitian terdiri atas data primer dan data sekunder. Data primer dikumpulkan melalui angket, sedangkan data sekunder bersumber dari literatur-literatur yang mendukung penelitian. Hasil penelitian menunjukkan bahwa masyarakat milenial memiliki sikap bahasa yang positif terhadap bahasa Indonesia. Artinya, masyarakat milenial masih intens menggunakan bahasa Indonesia dalam kesehariannya.
\end{abstract}

Kata kunci: bahasa Indonesia, masyarakat milenial, sikap bahasa, sosiolinguistik.

\section{Pendahuluan}

Dalam UUD 1945 dan UU nomor 24 tahun 2009 pasal 25-39 dinyatakan bahwa masyarakat Indonesia harus mengutamakan bahasa Indonesia. Sebagaimana dalam isi UU tersebut, kata 'utama' menjelaskan bahwa penguasaan bahasa Indonesia perlu diprioritaskan sebagai bahasa yang dominan digunakan sehari-hari. Bersamaan dengan revolusi industri 4.0, hal tersebut tentu memengaruhi sikap masyarakat terhadap bahasa Indonesia. Adanya persaingan global menjadikan bahasa Inggris sebagai bahasa internasional. Globalisasi pada abad ke-21 merupakan salah satu penyebab terjadinya perubahan bahasa di Indonesia. 
Dikarenakan batasan antarnegara ataupun antarmasyarakat untuk berinteraksi sudah runtuh. Adanya globalisasi semakin mempermudah manusia untuk mengakses segala informasi dan juga transportasi. Hal tersebut menyebabkan semakin mudahnya terjadi transfer kebudayaan. Perubahan yang terjadi tentu memiliki dampak positif dan negatif. Perubahan ke arah positif bersifat membangun, sedangkan dampak negatif yang ditimbulkan dapat mengubah bahasa dan juga penuturnya. Semakin seringnya terjadi kontak bahasa, maka akan mengakibatkan terjadinya seleksi bahasa (language selection) dan kematian bahasa (language death). Berkaitan dengan hal tersebut UU nomor 24 tahun 2009 pasal 43 berisi anjuran untuk menguasai bahasa asing. Hal ini sejalan pula dengan UUD 1945 pasal 32 dan UU nomor 24 tahun 2009 pasal 41-42 untuk tetap melestarikan bahasa daerah. Hal tersebut menunjukkan gambaran politik bahasa di Indonesia.

Bahasa berperan sebagai alat atau sarana kebudayaan, baik untuk perkembangan, transmisi, maupun sebagai inventaris. Masyarakat yang merupakan pengguna bahasa terbesar yaitu masyarakat milenial. Hal ini ditandai dari tahun kelahiran generasi milenial yang dimulai sejak tahun 1980-2000, sehingga dapat dikatakan bahwa kisaran usia masyarakat milenial sekitar 20-40 tahun. Oleh sebab itu, masyarakat milenial berpotensi mengubah pola bahasa biasa menjadi pola bahasa multilingual yang didominasi oleh bahasa asing dengan bantuan teknologi.

Crystal (2003), menyatakan bahwa bahasa Inggris merupakan bahasa internasional yang kerap digunakan dalam diplomasi, perdagangan, dan juga pendidikan di dunia [1]. Bahasa Inggris disebarkan melalui penjajahan Inggris, migrasi orang-orang yang berbahasa Inggris serta pengaruh Amerika Serikat. Di beberapa negara, bahasa Inggris dijadikan sebagai bahasa kedua setelah bahasa nasional negara itu sendiri. Contohnya, Singapura yang memiliki ikatan sejarah institusional dengan negara Inggris. Dewasa ini, berbagai sumber ilmu pengetahuan ditulis dan direpresentasikan dalam bahasa Inggris. Tujuannya yaitu untuk mempermudah komunikasi dengan Individu dari negara lain.

Negara Indonesia menjadikan bahasa Inggris sebagai salah satu bahasa asing yang wajib dipelajari, sehingga bahasa Inggris masuk ke dalam daftar mata pelajaran wajib di semua instansi pendidikan di Indonesia. Hal ini bertujuan agar semua masyarakat, khususnya masyarakat milenial, dapat bersaing dengan negara lain. Chaer dan Agustina (2010), menyebutkan bahwa penguasaan dua bahasa (bilingual), tiga bahasa (trilingual) maupun banyak bahasa (multilingual) memengaruhi pemakaian suatu bahasa sebagai bahasa yang utama digunakan dengan cara bergantian [2]. Dengan pemakaian bahasa yang dominan digunakan dapat menunjukkan bahwa sikap masyarakat positif terhadap bahasa tersebut. Meskipun terdapat persaingan bahasa, masyarakat milenial dipaksa memilih bahasa yang lebih memudahkannya dalam berkomunikasi. Penelitian ini bertujuan untuk mengetahui dan mendeksripsikan sikap bahasa masyarakat milenial terhadap bahasa Indonesia.

Perspektif bahwa bahasa Inggris lebih "gaul atau kekinian" dibandingkan dengan bahasa Indonesia dan bahasa daerah menjadi alasan lain dalam penggabungan bahasa ataupun persaingan dengan bahasa Indonesia sendiri. Kemampuan masyarakat milenial menguasai lebih dari satu bahasa, bilingual dan trilingual berhubungan dengan pendapat Wardhaugh (1992) bahwa bilingualisme dan multilingualisme disebabkan oleh beberapa faktor, antara lain karena perpindahan penduduk (oleh para imigran), pengunjung suatu masyarakat, perkawinan antara dua orang yang menggunakan bahasa/kode yang berbeda, perdagangan, pendidikan, dan karena berhubungan dengan dunia internasional [3]. Chaer (2010: 144), menyebutkan bahwa pergeseran bahasa biasanya terjadi di negara, daerah, atau wilayah yang memberi harapan untuk kehidupan sosial ekonomi yang lebih baik, sehingga mengundang 
imigran/transmigran untuk mendatanginya [2]. Kemampuan tersebut dapat menjadi pilihan dalam penggunaan bahasa masyarakat.

Kesadaran berbahasa perlu ditanamkan kepada masyarakat dengan tujuan untuk menentukan intensitas pemakaian bahasa, baik bahasa Indonesia, bahasa daerah, atau bahasa asing yang digunakan secara bergiliran. Sikap bahasa masyarakat milenial merupakan bentuk nyata terhadap bahasa apa yang nantinya lebih berperan sebagai alat komunikasi. Hal ini tentunya didukung pula oleh lokasi pemakaian bahasa itu digunakan, sehingga posisi masyarakat milenial yang berada di Indonesia pada saat ini harus menentukan cara pemakaian bahasanya sebagai gambaran sikap bahasa terhadap bahasa Indonesia.

Winarti (2015), dalam tulisannya yang berjudul Sikap Bahasa Masyarakat di Wilayah Perbatasan NTT: Penelitian Sikap Bahasa Pada Desa Silawan, Provinsi Nusa Tenggara Timur, memusatkan pembahasannya pada sikap bahasa masyarakat di Desa Silawan terhadap bahasa daerah, bahasa Indonesia, dan bahasa asing [4]. Masyarakat yang diteliti dikelompokkan berdasarkan jenis kelamin, tingkat usia, jenjang pendidikan, etnis pasangan, status perkawinan, dan tempat tinggal. Hasil kajiannya menyebutkan bahwa masyarakat Desa Silawan memiliki sikap positif terhadap bahasa daerah dibandingkan dengan bahasa Indonesia. Alimin, Hariyadi, dan Safrihady (2017) dalam tulisannya yang berjudul Sikap Bahasa Mahasiswa Program Studi Pendidikan Bahasa Inggris terhadap Bahasa Indonesia menyatakan bahwa sikap bahasa dan kebanggaan berbahasa Indonesia mahasiswa program studi Pendidikan Bahasa Inggris di atas 70\% [5]. Tulisan Sulastriana (2017) yang berjudul Sikap Bahasa dan Pemilihan Bahasa Mahasiswa Urban di IKIP PGRI Pontianak menjelaskan bahwa mahasiswa urban cenderung bersikap positif terhadap bahasa daerahnya dan bahasa Indonesia [6]. Sedangkan Mulyaningsih (2017), dalam tulisannya yang berjudul Sikap Bahasa terhadap Bahasa Indonesia menjelaskan bahwa sikap bahasa mahasiswa perguruan tinggi di Cirebon memiliki sikap positif terhadap bahasa Indonesia [7]. Hal itu ditandai dengan kemampuan para mahasiswa dalam memahami kaidah bahasa Indonesia, kesadaran akan pentingnya bahasa Indonesia, kebanggaan berbahasa Indonesia, dan keyakinan bahwa bahasa Indonesia akan terus eksis. Dengan melihat empat hasil penelitian yang telah dipaparkan di atas, maka penelitian ini akan berfokus pada masyarakat milenial yang lahir pada tahun 19802000. Lalu, sikap masyarakat milenial terhadap bahasa Indonesia akan dilihat dari intensitasnya menggunakan bahasa Indonesia, sehingga untuk mengetahui bahasa yang paling intens digunakan akan dibandingkan dengan intensitas penggunaan bahasa daerah dan bahasa asing.

Sikap bahasa secara garis besar membicarakan tentang sikap penutur dalam menerima atau menolak suatu bahasa. Sikap bahasa dianggap sebagai sebuah dominansi penggunaan bahasa terhadap bahasa lainnya untuk berkomunikasi. Juga menggambarkan bentuk perasaan senang atau tidak senang seorang penutur terhadap suatu bahasa yang digunakannya. Sikap kebahasaan ialah sebuah norma kepercayaan atau kognisi yang memiliki rentang waktu yang panjang. Selain itu, sikap bahasa tidak hanya berasal dari dorongan dalam diri saja, tetapi sikap bahasa pun dapat dipengaruhi oleh faktor eksternal atau lingkungan terdekatnya.

Holmes (2013: 410) menyebutkan bahwa orang-orang secara umum tidak memiliki pendapat tentang bahasa dalam keadaan hampa [8]. Dengan kata lain, tidak ada konsensus universal tentang bahasa mana yang paling indah dan yang paling jelek terlepas dari kepercayaan bahwa beberapa bahasa secara inheren lebih indah daripada yang lain. Selain itu, sikap bahasa sangat dipengaruhi oleh faktor sosial dan politik. Masyarakat mengembangkan sikap terhadap bahasa ketika bertemu dengan orang memiliki aksen bahasa yang berbeda dengan mereka, kemudian menghubungkannya dengan fungsi dan konteks terkait. 
Penggunaan bahasa tidak akan pernah terlepas dari upaya mempertahankan bahasa dan pergeseran bahasa. Ketika sebuah bahasa dipertahankan, maka akan ada bahasa lain yang mengalami pergeseran. Mesthrie, Swann, Deumert, dan Leap (2009: 245) menjelaskan bahwa pemeliharaan bahasa dilakukan dengan penggunaan bahasa secara berkelanjutan guna menghadapi persaingan dari bahasa yang lebih kuat secara regional dan sosial [9]. Holmes (2013: 53) melanjutkan bahwa penggunaan bahasa asing yang dituturkan oleh masing-masing individu atau kelompok secara terus menurus, seiring berjalannya waktu dapat menggantikan bahasa ibu yang lambat laut menjadi bahasa minoritas [8]. Holmes juga menyebutkan bahwa ada banyak sekali faktor sosial yang berbeda yang menyebabkan komunitas bergeser dari menggunakan satu bahasa untuk berganti ke bahasa yang lain untuk kebutuhan komunikasi mereka. Contoh nyata dari proses pergeseran bahasa adalah keluarga migran. Menurut Sumarsono (2002: 231), pergeseran bahasa berarti suatu guyup (komunitas) meninggalkan suatu bahasa sepenuhnya untuk memakai bahasa lain [10]. Sementara itu, jika suatu guyup memilih untuk tetap memakai bahasa tersebut maka itu berarti guyup tersebut sedang mempertahankan bahasanya. Kondisi ini terjadi dalam jangka yang panjang, setidaknya tiga generasi. Hal tersebut tergantung pada sikap bahasa penutur.

Pateda (2015: 34)menyebutkan bahwa sikap bahasa dapat dilihat dari dua segi yaitu sikap positif dan sikap negatif [11]. Sikap positif terhadap bahasa dapat dilihat dari cara seorang penutur dalam menghargai bahasa yang digunakannya, sedangkan sikap negatif sebaliknya. Sikap bahasa secara garis besar membicarakan perihal sikap penutur untuk menerima atau menolak suatu bahasa. Sementara itu, menurut Garvin dan Mathiot (dalam Chaer, 2010), ciriciri seorang penutur memiliki sikap positif terhadap bahasa bisa ditinjau dari tiga ciri, yaitu kesetiaan bahasa (language loyalty) mendorong penuturnya untuk tetap mempertahankan bahasanya, kebanggaan bahasa (language pride) mendorong penuturnya untuk memperluas atau mengembangkan bahasa yang dipakainya dan dipakai sebagai identitas untuk kesatuan kelompoknya, dan kesadaran akan norma bahasa (awareness of the norm) mendorong penuturnya untuk memakai bahasa secara cermat dan santun [2]. Chaer (2010: 152), menyebutkan bahwa sikap negatif terhadap suatu bahasa dapat terjadi apabila penutur asli bahasa tersebut sudah tidak lagi memiliki rasa bangga terhadap bahasanya sendiri, sehingga mengalihkan rasa bangga itu kepada bahasa lain yang bukan miliknya [2]. Sementara itu, Malabar (2015: 64)menyebutkan bahwa sikap negatif terhadap bahasa merupakan sikap yang tidak bertanggung jawab terhadap bahasa nasionalnya [12]. Ia akan beranggapan bahwa bahasa negara lain lebih baik dari bahasa nasional, sehingga timbul sikap negatif terhadap bahasa.

\section{Metode}

Penelitian ini merupakan penelitian kuantitatif-deskriptif dengan pendekatan teoritis Sosiolinguistik. Penelitian ini akan mendeskripsikan data yang telah diperoleh secara apa adanya dan disimpulkan sikap bahasa masyarakat milenial terhadap bahasa Indonesia. Data penelitian ini terdiri dari data primer dan data sekunder. Data primer pada penelitian ini adalah hasil angket, sedangkan data sekunder penelitian ini adalah literatur-literatur lainnya yang mendukung penelitian. Instrumen yang digunakan dalam penelitian ini berupa angket (googleform). Objek pada penelitian ini adalah 50 orang masyarakat milenial yang memiliki rentang usia 20-40 tahun. Data dianalisis menggunakan model analisis Miles dan Huberman. 


\section{Hasil dan Pembahasan}

Berdasarkan data penelitian yang diolah dengan bantuan program SPSS, didapatkan 16 tabel hasil dari sikap bahasa masyarakat milenial terhadap bahasa Indonesia.

Tabel 1. Bahasa yang Digunakan dengan Teman Sebaya di Rumah.

\begin{tabular}{ccc|c|c} 
& & Frequency & Percent & $\begin{array}{c}\text { Cumulative } \\
\text { Percent }\end{array}$ \\
\hline \multirow{3}{*}{ Valid } & Daerah & 17 & 34.0 & 34.0 \\
\cline { 2 - 5 } & Indonesia & 33 & 66.0 & 100.0 \\
\cline { 2 - 5 } & Total & 50 & 100.0 & \\
\hline
\end{tabular}

Tabel 2. Bahasa yang Digunakan di Lingkungan Keluarga.

\begin{tabular}{cccc|c} 
& & Frequency & Percent & Cumulative Percent \\
\hline \multirow{3}{*}{ Valid } & Daerah & 24 & 48.0 & 48.0 \\
\cline { 2 - 5 } & Indonesia & 26 & 52.0 & 100.0 \\
\cline { 2 - 5 } & Total & 50 & 100.0 & \\
\hline
\end{tabular}

Tabel 3. Bahasa yang Digunakan di Media Sosial untuk Menulis Keterangan Gambar.

\begin{tabular}{ccc|c|c} 
& & Frequency & Percent & Cumulative Percent \\
\hline \multirow{5}{*}{ Valid } & Daerah & 1 & 2.0 & 2.0 \\
\cline { 2 - 5 } & Indonesia & 40 & 80.0 & 82.0 \\
\cline { 2 - 5 } & Asing & 9 & 18.0 & 100.0 \\
\cline { 2 - 5 } & Total & 50 & 100.0 & \\
\hline
\end{tabular}

Tabel 4. Bahasa yang Digunakan di Media Sosial untuk Membalas Pesan Teman.

\begin{tabular}{ccc|c|c} 
& & Frequency & Percent & Cumulative Percent \\
\hline \multirow{7}{*}{ Valid } & Daerah & 4 & 8.0 & 8.0 \\
\cline { 2 - 5 } & Indonesia & 44 & 88.0 & 96.0 \\
\cline { 2 - 5 } & Asing & 2 & 4.0 & 100.0 \\
\cline { 2 - 5 } & Total & 50 & 100.0 & \\
\hline
\end{tabular}

Tabel 5. Bahasa yang Digunakan untuk Berkomentar di Media Sosial.

\begin{tabular}{cccccc} 
& & Frequency & Percent & Cumulative Percent \\
\hline \multirow{3}{*}{ Valid } & Indonesia & 47 & 94.0 & 94.0 \\
\cline { 2 - 5 } & Asing & 3 & 6.0 & 100.0 \\
\cline { 2 - 5 } & Total & 50 & 100.0 & \\
\hline
\end{tabular}

Tabel 6. Bahasa yang Digunakan dengan Teman Sebaya di Kampus/Tempat Kerja.

\begin{tabular}{ccc|c|c} 
& & Frequency & Percent & Cumulative Percent \\
\hline \multirow{3}{*}{ Valid } & Daerah & 3 & 6.0 & 6.0 \\
\cline { 2 - 5 } & Indonesia & 46 & 92.0 & 98.0 \\
\cline { 2 - 5 } & Asing & 1 & 2.0 & 100.0 \\
\cline { 2 - 5 } & Total & 50 & 100.0 & \\
\hline
\end{tabular}


Tabel 7. Bahasa yang Digunakan Ketika Marah atau Mengumpat.

\begin{tabular}{cccccc} 
& & Frequency & Percent & Cumulative Percent \\
\hline Valid & Daerah & 22 & 44.0 & 44.0 \\
\cline { 2 - 5 } & Indonesia & 22 & 44.0 & 88.0 \\
\cline { 2 - 5 } & Asing & 6 & 12.0 & 100.0 \\
\cline { 2 - 5 } & Total & 50 & 100.0 & \\
\hline
\end{tabular}

Tabel 8. Bahasa yang Digunakan dengan Orang yang Tidak Dikenal di Jalan.

\begin{tabular}{cccccc} 
& & Frequency & Percent & Cumulative Percent \\
\hline \multirow{3}{*}{ Valid } & Daerah & 1 & 2.0 & 2.0 \\
\cline { 2 - 5 } & Indonesia & 49 & 98.0 & 100.0 \\
\cline { 2 - 5 } & Total & 50 & 100.0 & \\
\hline
\end{tabular}

Tabel 9. Bahasa yang Digunakan Ketika Menawar Harga Barang.

\begin{tabular}{ccccc} 
& & Frequency & Percent & Cumulative Percent \\
\hline \multirow{3}{*}{ Valid } & Daerah & 11 & 22.0 & 22.0 \\
\cline { 2 - 5 } & Indonesia & 39 & 78.0 & 100.0 \\
\cline { 2 - 5 } & Total & 50 & 100.0 & \\
\hline
\end{tabular}

Tabel 10. Bahasa yang Paling Fasih Diucapkan.

\begin{tabular}{ccc|c|c} 
& & Frequency & Percent & Cumulative Percent \\
\hline \multirow{3}{*}{ Valid } & Daerah & 10 & 20.0 & 20.0 \\
\cline { 2 - 5 } & Indonesia & 40 & 80.0 & 100.0 \\
\cline { 2 - 5 } & Total & 50 & 100.0 & \\
\hline
\end{tabular}

Berdasarkan data di atas yang berkaitan dengan lingkungan rumah didapatkan hasil bahwa bahasa yang lebih dominan digunakan adalah bahasa Indonesia. Hal tersebut dibuktikan dari persentase penggunaan bahasa Indonesia yang lebih besar dibandingkan bahasa daerah. Dapat dilihat pada tabel bahasa yang digunakan di lingkungan rumah, baik kepada teman sebaya maupun keluarga, persentase yang diperoleh sudah melebihi $50 \%$. $66 \%$ dari $100 \%$ masyarakat milenial memilih menggunakan bahasa Indonesia kepada teman sebaya di lingkungan sekitar rumahnya. Sejalan dengan itu, 52\% dari 100\% masyarakat milenial memilih menggunakan bahasa Indonesia saat berada di lingkungan keluarga. Tentunya ini membuktikan pengguna bahasa terhadap bahasa Indonesia menunjukkan sikap positif. Hasil tersebut juga menunjukkan bahwa bahasa Indonesia lebih intens digunakan dalam kehidupan. Berbeda dengan sikap negatif pengguna bahasa terhadap bahasa asing. Penggunaan bahasa Indonesia di lingkungan rumah didapatkan lebih dominan karena bahasa Indonesia merupakan bahasa pemersatu dengan masyarakat yang heterogen. Sementara, bahasa daerah masih kerap hadir pada bahasa sehari-hari sebab sebagian besar orang-orang tua masih memegang teguh kelestarian budaya terutama pada bahasa daerah.

Media sosial yang dapat digunakan oleh seluruh manusia di dunia, tidak terbatas pada wilayah, negara, ataupun benua. Dalam bermedia sosial, pengguna dapat mengirim unggahan baik berupa tulisan, gambar, atau tulisan dan gambar tergantung media sosial yang digunakan. Lalu, pengguna juga dapat membalas pesan teman baik yang sebaya, lebih tua, atau lebih muda. Serta, media sosial pun dapat digunakan untuk berkomentar unggahan orang lain. Interaksi tersebut tentu tidak hanya diketahui oleh satu atau dua orang saja. Tujuan membuat unggahan, mengirim pesan, dan berkomentar pun agar dilihat oleh banyak orang. Agar semua pengguna media sosial dapat memahami isi unggahan dan maksud komentar, mayoritas 
pengguna media sosial menggunakan bahasa persatuan atau bahasa Indonesia dalam berinteraksi di media sosial. Tidak terkecuali mengirim pesan kepada teman melalui media sosial. Ketiga hal itu menunjukkan adanya intensitas pemakaian bahasa Indonesia oleh pengguna media sosial yang sangat tinggi.

Berdasarkan data yang telah didapatkan, $80 \%$ dari $100 \%$ pengguna media sosial memilih menggunakan bahasa Indonesia untuk menulis keterangan gambar dalam unggahannya di media sosial. Lalu, $88 \%$ dari $100 \%$ pengguna media sosial memilih menggunakan bahasa Indonesia untuk membalas pesan teman di media sosial. Serta, 94\% dari 100\% pengguna media sosial menggunakan bahasa Indonesia dalam berkomentar di media sosial. Ketiga data tersebut dapat membuktikan bahwa pengguna media sosial yang termasuk ke dalam masyarakat milenial lebih memilih menggunakan bahasa Indonesia. Mereka intens menggunakan bahasa Indonesia dalam berinteraksi di media sosial. Hal itu menunjukkan sikap bahasa masyarakat milenial terhadap bahasa Indonesia, khususnya dalam bermedia sosial adalah sikap positif. Tidak hanya dalam bermedia sosial saja, masyarakat milenial pun lebih memilih menggunakan bahasa Indonesia saat di kampus ataupun tempat kerja. Salah satu yang menjadi faktor pemilihan bahasa Indonesia di lingkungan kampus dan tempat kerja adalah keformalan dan keprofesionalan. Serta, di lingkungan kampus dan tempat kerja merupakan lingkungan yang heterogen dan tidak semua berasal dari tempat asal yang sama. Berdasarkan data yang telah didapatkan, $92 \%$ dari $100 \%$ masyarakat milenial memilih menggunakan bahasa Indonesia daripada bahasa daerah dan bahasa asing. Hal itu menunjukkan bahwa masyarakat milenial memiliki sikap positif terhadap bahasa Indonesia dalam berinteraksi dengan teman di kampus atau tempat kerja.

Masyarakat milenial dalam kehidupan sehari-hari lebih dominan menggunakan bahasa Indonesia, sehingga hal ini menunjukkan sikap positif. Hal ini dibuktikan melalui persentase penggunaan bahasa Indonesia yang digunakan oleh masyarakat milenial ketika marah atau mengumpat dengan persentase $44 \%$ atau 22 orang dari 50 orang responden. Lalu, saat berinteraksi dengan orang yang tidak dikenal di jalan pun tetap menunjukkan sikap positif, terlihat dari persentase $98 \%$ atau 49 orang memilih menggunakan bahasa Indonesia. Sikap positif juga ditunjukkan pada bahasa yang digunakan dalam menawar harga barang yaitu 39 orang atau $78 \%$. Data-data dominansi bahasa Indonesia yang digunakan oleh masyarakat milenial dalam kegiatannya sehari-hari, ditunjukkan oleh bahasa yang paling fasih diucapkan yaitu bahasa Indonesia dengan persentase $80 \%$ atau 40 orang.

Berdasarkan 10 tabel yang didapatkan, seluruh tabel menunjukkan bahasa Indonesia lebih dominan digunakan dibandingkan bahasa daerah maupun bahasa asing. Hal ini membuktikan bahasa Indonesia intens digunakan pada keseharian. Bahkan pada beberapa tabel, seperti tabel bahasa yang digunakan pada teman sebaya dikampus/tempat kerja, berkomentar di media sosial, dan berbicara dengan orang yang tidak dikenal persentase yang diperoleh $92-98 \%$. Dengan begitu, perbedaan intensitas penggunaan bahasa Indonesia dengan bahasa lainnya sangat signifikan. Maka dari itu, intensitas tersebut membuktikan sikap positif terhadap bahasa Indonesia.

\section{Simpulan}

Berdasarkan 10 tabel sikap bahasa di atas, dapat diketahui bahwa masyarakat milenal mayoritas menggunakan bahasa Indonesia daripada bahasa daerah dan bahasa asing dalam berkomunikasi, baik secara verbal ataupun nonverbal. Hal tersebut menunjukan bahwa 
masyarakat milenial memilih menggunakan bahasa Indonesia sebagai bahasa yang dominan dalam berkomunikasi. Sikap tersebut termasuk ke dalam sikap positif dalam berbahasa, karena penutur lebih mempertahankan bahasa Indonesia daripada bahasa asing. Penelitian ini memberikan sumbangsih terhadap perkembangan ilmu pengetahuan terkait sikap bahasa masyarakat milenial berdasarkan intensitas bahasa yang digunakan. Intensitas ini tidak terikat pada jenis kelamin, tempat tinggal, jenjang pendidikan, dan profesi.

\section{Referensi}

[1] Crystal D. English as Global Language. Cambridge: Cambridge University Press; 2003.

[2] Chaer A., dan L. Agustina. Sosiolinguistik: Perkenalan Awal. Jakarta: Rineka Cipta; 2010.

[3] Wardhaugh R. Introduction to Sociolinguistics. Second Edition. Massachusetts: Blackwell Publisher Ltd; 1992.

[4] Winarti S. Sikap Bahasa Masyarakat di Wilayah Perbatasan NTT: Penelitian Sikap Bahasa pada Desa Silawan. Metalingua. 2015; 13 (2): 215-227.

[5] Alimin AA, Hariyadi, Safrihady. Sikap Bahasa Mahasiswa Program Studi Pendidikan Bahasa Inggris terhadap Bahasa Indonesia. JP-BSI. 2017; 2 (1): 36-40.

[6] Sulastriana E. Sikap Bahasa dan Pemilihan Bahasa Mahasiswa Urban di IKIP PGRI Pontianak. Jurnal Pendidikan Bahasa. 2017; 6 (2): 258-270.

[7] Mulyaningsih I. Sikap Mahasiswa terhadap Bahasa Indonesia. Journal Indonesian Language Education and Literature. 2017; 3 (1): 79-87.

[8] Holmes J. An Introduction to Sociolinguistics. Fourth Edition. London dan New York: Routledge; 2013.

[9] Mesthrie R., dkk. Introduction Sociolinguistics. Second Edition. Edinburgh: Edinburgh University Press; 2009.

[10] Sumarsono. Sosiolinguistik. Yogyakarta: Pustaka Pelajar; 2017.

[11] Pateda M. Sosiolinguistik. Bandung: CV Angkasa; 2015.

[12] Malabar S. Sosiolinguistik. Gorontalo: Ideas Publishing; 2015. 